\title{
Author Correction: Comparing phenotypic variation between inbred and outbred mice
}

Alexander H. Tuttle, Vivek M. Philip, Elissa J. Chesler (DD and Jeffrey S. Mogil (DD

Correction to: Nature Methods https://doi.org/10.1038/s41592-018-0224-7, published online 30 November 2018

In the version of this Comment originally published, the authors omitted a funding source. Grant 5 P50 DA039841 (to E.J.C.) from the US National Institute on Drug Abuse has been added to the Acknowledgements in the HTML and PDF versions of the paper.

Published online: 21 December 2018

https://doi.org/10.1038/s41592-018-0298-2

\section{Publisher Correction: Sequence meets space}

Tal Nawy

Correction to: Nature Methods https://doi.org/10.1038/s41592-018-0243-4, published online 30 November 2018

The originally published version of this Research Highlight incorrectly stated that Guo-Cheng Yuan is at the University of California at Los Angeles; the correct affiliation is Dana-Farber Cancer Institute. The text has been corrected in the HTML and PDF versions of the paper.

Published online: 21 December 2018

https://doi.org/10.1038/s41592-018-0299-1

\section{Publisher Correction: Stability, affinity, and chromatic variants of the glutamate sensor iGluSnFR}

Jonathan S. Marvin D, Benjamin Scholl, Daniel E. Wilson, Kaspar Podgorski, Abbas Kazemipour, Johannes Alexander Müller (D), Susanne Schoch, Francisco José Urra Quiroz, Nelson Rebola, Huan Bao, Justin P. Little, Ariana N. Tkachuk, Edward Cai, Adam W. Hantman, Samuel S.-H. Wang, Victor J. DePiero, Bart G. Borghuis (D, Edwin R. Chapman, Dirk Dietrich, David A. DiGregorio, David Fitzpatrick and Loren L. Looger (D)

Correction to: Nature Methods https://doi.org/10.1038/s41592-018-0171-3, published online 30 October 2018

In the version of this paper originally published, important figure labels in Fig. 3d were not visible. An image layer present in the authors' original figure that included two small dashed outlines and text labels indicating ROI 1 and ROI 2, as well as a scale bar and the name of the cell label, was erroneously altered during image processing. The figure has been corrected in the HTML and PDF versions of the paper.

Published online: 2 January 2019

https://doi.org/10.1038/s41592-018-0300-z 